\title{
Targeted polymerase chain reaction-based expression of putative halitogenic bacteria and volatile sulphur compound analysis among halitosis patients at a tertiary hospital in Nigeria
}

\author{
Adeyinka Happy Adedapo ${ }^{1} \cdot$ Bamidele Kolude $^{1} \cdot$ Hannah Odunola Dada-Adegbola $^{2} \cdot J_{0}$. Hathan Olujare Lawoyin $^{1}$. \\ Henry Ademola Adeola ${ }^{3,4}$ (D)
}

Received: 2 August 2019 / Accepted: 26 September 2019 / Published online: 22 October 2019

(c) The Society of The Nippon Dental University 2019

\begin{abstract}
Halitosis (bad breath) can be a cause of anxiety, depression and psychosocial stress, with pathological changes in the oral microbiota playing an important role in its development. Despite its prevalence, studies on the microbiology of halitosis are rare in Nigeria. This study determines the presence of five putative periodontal pathogens viz: Actinobacillus actinomycetemcomitans, Fusobacterium nucleatum, Porphyromonas gingivalis, Prevotella intermedia and Treponema denticola on the tongue dorsa of halitosis and non-halitosis patients using a 16S rDNA-directed polymerase chain reaction assay. Furthermore, an association of these bacteria with oral malodour [as assessed by volatile sulphur compounds (VSC) measurements] with a portable sulphide monitor, the Halimeter (Interscan Corp, Chatsworth, California), was performed. The results showed that the prevalence of halitosis in this environment as defined by VSC level above $160 \mathrm{ppb}$ is $14.9 \%$. Halitosis is affected by gender with males having it more than the females. Males also tend to present more with self-reported complaints of halitosis than females. Age does not appear to contribute to the incidence of halitosis. Fusobacterium nucleatum, P. gingivalis, $P$. intermedia are responsible for increased production of VSCs in halitosis patients while A. actinomycetemcomitans and T. denticola appear to play no part in the production of VSCs. Evaluation of halitogenic bacteria and VSCs may potentially become a surrogate biomarker for monitoring halitosis. Targeted assessment of putative halitogenic bacteria may provide a rapid point-of-care diagnostic tool for halitosis.
\end{abstract}

Keywords Halitosis · Halitogenic bacteria · Volative sulphur compounds · Halimeter · Polymerase chain reaction

\section{Introduction}

Halitosis is the common term used to define an unpleasant or an offensive odour in expired air, regardless of whether it originates from oral or non-oral sources. Other terms include

Henry Ademola Adeola

henry.adeola@uct.ac.za

1 Department of Oral Pathology, College of Medicine, University of Ibadan, Ibadan, Nigeria

2 Department of Medical Microbiology and Parasitology, College of Medicine, University of Ibadan, Ibadan, Nigeria

3 Department of Oral and Maxillofacial Pathology, Faculty of Dentistry, University of the Western Cape and Tygerberg Hospital, Cape Town, South Africa

4 Division of Dermatology, Department of Medicine, Faculty of Health Sciences and Groote Schuur Hospital, University of Cape Town, Observatory 7925, Cape Town, South Africa fetor ex ore, breath malodor, oral malodour, or offensive breath [1]. About $98 \%$ of halitosis originates from the oral cavity [2].

Oral sources of halitosis mentioned in the literature are tongue coating, periodontal diseases, pericoronitis, impacted food and debris, unclean dentures, decreased salivary flow rate, gastro-oesophageal reflux, mucosal ulcerations and diseases, and habitual mouth breathing (especially in children) $[2,3]$. Non-oral etiologies of halitosis include disturbances of the upper and lower respiratory tract, some systemic diseases, metabolic disorders, medications and carcinomas [4]. A recent possible link has been suggested between Helicobacter pylori (in peptic ulcers) and halitosis [5].

Consumption of certain food and drinks, such as spices, garlic, onion, curries, cabbage, cauliflower and radish, or habits such as smoking tobacco or drinking alcohol, results in a transient halitosis caused by sulphur-containing volatile agents [6-8]. In addition, drugs like isosorbide dinitrate, 
disulfiram, diamines (e.g. cadaverine, putrescine), methylamine, dimethylamine, propionic acid, butyric acid, indole, and skatole, have also been implicated [6, 9-12]. Some of these medications have been hypothesized to modify rather than cause malodour [13].

Halitosis specifically is primarily the result of the microbial metabolism of amino acids in local debris from food substances, desquamated epithelium and dead polymorphonuclear cells [14]. Many of the compounds that contribute to oral malodour are volatile sulphur compounds (VSCs) such as hydrogen sulphide $\left(\mathrm{H}_{2} \mathrm{~S}\right)$, methylmercaptan $\left(\mathrm{CH}_{3} \mathrm{SH}\right)$ and dimethylsulphide $\left(\mathrm{CH}_{3} \mathrm{SCH}_{3}\right)$ [15], and they account for approximately $90 \%$ of oral malodour $[5,16]$.

The portable sulphide monitors such as the Halimeter (Interscan Corp, Chatsworth, California) can be used to measure the level of intraoral volatile sulphur compounds (VSCs) at the dental chair side to provide an objective quantification of halitosis. (Sensors for VSCs have been incorporated into probes and paddles, which can be placed directly on the tongue for measurement (Diamond Probe, Ann Arbor, Michigan) [17]. More recent advances are in the field of a VSC monitor, which uses a zinc oxide sensor (electronic nose) which is a more objective quantification of halitosis [18].

Replogle and Beebe [19] also demonstrated that the intensity of clinical bad breath is significantly associated with amount of intra oral VSC levels. A high level of VSCs in the body accelerates destruction of periodontal tissues which further explains why patients with periodontal disease often complain of oral malodour [20].

Although less than $50 \%$ out of the over 700 bacterial species or phylotypes colonizing the human body have been detected in the oral cavity [21], several dozens of those found in the mouth can be pathogenic when allowed to flourish or are genetically disposed to overpopulate. Therefore, the problem of oral malodour has been shown to originate in the oral cavity where conditions favour the retention of anaerobic bacteria especially during sleep because the proliferation of oral microorganisms associated with nocturnal hypo-salivation is responsible for the greater production of VSCs that promotes morning bad breath, even in periodontally healthy subjects [22].

Furthermore, periodontopathic bacteria, such as Prevotella intermedia, Porphyromonas gingivalis, Fusobacterium nucleatum, Treponema denticola, Veillonella parvula, Peptostreptococcus spp. and Actinobacillus actinomycetecomitans are capable of producing hydrogen sulphide, dimethylsulphide and methylmercaptan in large quantities [23-26]. Recent studies utilizing direct amplification of bacterial nucleic acids (using PCR) rather than traditional microbiological culture have also identified a new group of bacteria residing on the dorsal surface of the tongue in subjects with oral halitosis. These include Atopobium parvulum,
Firmicutes species, Dialister species, Fusobacterium periodonticum, Granulicatella elegens, Eubacterium sulci, Staphylococcus warneri and TM7 Species [27, 28].

Many studies focusing on treatment of halitosis through tongue cleaning, have demonstrated that VSC scores can be significantly reduced especially when the posterior part of the dorsum of the tongue is thoroughly cleansed [29-32] showing that the tongue is a major site of oral malodour production, whereas periodontal disease and other factors seem only a fraction of the overall problem [33-35]. The tongue is also known to harbour a very diverse flora at high cell density making it recognizable as the major site of malodour generation in the oral cavity [36-40]. Gram-negative anaerobes such as $P$. gingivalis, $P$. intermedia, Tannerella forsythensis (previously known as Bacteroides forsythus), and $F$. nucleatum are the organisms with the greatest malodour forming potential on the tongue [41-43]. Hence, the purpose of this study is to determine the presence of five oral pathogens namely, Actinobacillus actinomycetemcomitans, $F$. nucleatum, $P$. gingivalis, $P$. intermedia and $T$. denticola on the tongue dorsa of halitosis and non-halitosis patients using a 16S rDNA-directed polymerase chain reaction (PCR) assay and to examine the association of these bacteria with oral malodour as assessed by VSCs measurements of the two groups, using a portable sulphide monitor, the Halimeter (Interscan Corp, Chatsworth, California).

\section{Materials and methods}

\section{Study population}

This prospective study was conducted among self-reported and examined halitosis and non-halitosis subjects at the Oral Diagnosis Clinic, University College Hospital, Ibadan (U.C.H) from June 2008 to June 2010. A rigorous screening protocol described by Donaldson et al. [44], was used to identify subjects suffering from halitosis which was not related to chronic gingivitis, chronic periodontitis or pathology of the oral mucosa. Subjects were asked to avoid eating foods containing garlic, onions and strong spices, and to refrain from consuming alcohol, smoking and using mouthwashes, $48 \mathrm{~h}$ prior to assessment. On the morning of assessment, they were asked to refrain from drinking coffee, using mint containing products like chewing gums and mouth drops and wearing heavily scented products. Subjects were also asked to have a light breakfast no less than $3 \mathrm{~h}$ before the assessment and to rinse their mouth with water to remove plaque deposits and food debris immediately after breakfast. Control patients were those that come to the oral diagnosis clinic for routine scaling and polishing with no complaint of halitosis. The two groups were matched for age, sex and socioeconomic status. 
Informed consent was then obtained from all enrolled individuals.

\section{Ethical considerations}

Demographic data obtained from the records of the patients were kept confidential and accessible to the principal investigator only. Patients were deidentified using codes and data were transferred to a password protected personal computer. Full ethical clearance was obtained from the Joint University of Ibadan/ University College Hospital Ethical Review Committee (Ethical approval \# UI/EC/10/0032).

\section{Inclusion criteria}

All patients previously treated for halitosis that consented to participate in the study.

1. Must have good oral hygiene, no periodontal disease.

2. All respondents with no fewer than 20 standing teeth including at least one molar and one bicuspid in each quadrant of the dentition.

3. Participants must not be using a removable partial denture.

4. They must be between ages 10-45 years when full complement of permanent teeth is expected to have erupted.

\section{Exclusion criteria}

Applying the screening protocol of Donaldson et al. [44], the following criteria were used to exclude participants:

1. Individuals with poor oral hygiene (Grade 3.1-6.0 on the community periodontal index of treatment needs (CPITN) scale).

2. Generalized chronic gingivitis or periodontitis or pericoronitis.

3. Pathology of the oral mucous membranes or attached gingiva.

4. Respiratory tract diseases.

5. Diabetes mellitus.

6. Kidney, liver or stomach disorders.

7. Sjögren's syndrome.

8. Antibiotic therapy in the preceding 4 weeks.

9. Patients on medications that can cause xerostomia.

10. Complete edentulousness and use of removable partial denture.

11. Patients who smoke.

\section{Sample size}

Sample size $(n)$ calculation by comparing proportions, gave a minimum sample size of 31 among cases and 31 among controls. The patients were matched for age, sex and socioeconomic status.

\section{Measurement of volatile sulphur compounds}

VSCs measurements were made with a portable industrial sulphide monitor (Interscan Corp., Chatsworth, CA), zeroed on ambient air before each measurement. A disposable $8.5 \mathrm{~cm}$ plastic straw was attached to the air inlet of the monitor. The halimeter straw was partially inserted into the patients mouth to the length of $4 \mathrm{~cm}$ into the oral cavity and mouth closed around the straw. Patients were asked to breathe through the nose during the measurement. This instrument contained a pump which sucked air from the plastic straw placed inside the patient's mouth at $1500 \mathrm{~mL} / \mathrm{min}$. The sample of mouth air passed through a sensor, which registered the level of sulphides. Both peak (maximum) and steady-state levels attained were then determined in parts per billion ( $\mathrm{ppb}$ ) sulphide equivalents by direct readings from the analog scale of the monitor. Three separate readings were taken for each patient and the mean values for all the readings were recorded and used for statistical analysis.

\section{Sample collection}

A sample specimen from each subject was collected from the dorsum of the tongue of each subject anterior to the circumvallate papillae by scraping the tongue surface from the vallate papilla area to the anterior tongue border with a sterile wooden spatula. The tongue scraping on the spatula was removed using a sterile paper point and placed into a test tube containing $1 \mathrm{ml}$ of thioglycolate solution and immediately stored at $-20{ }^{\circ} \mathrm{C}$ until processed.

\section{Bacterial identification by PCR}

\section{DNA extraction}

Clinical specimens placed in thioglycollate medium and stored at $-20{ }^{\circ} \mathrm{C}$ were thawed to $37{ }^{\circ} \mathrm{C}$ by dipping it in a water bath for $10 \mathrm{~min}$ and vortex-mixed for $1 \mathrm{~min}$. Microbial suspension was then washed three times in $1 \mathrm{ml}$ of ultra-pure water by centrifuging at $12,000 \times g$ for $5 \mathrm{~min}$ and the supernatant was collected for DNA extraction and purification using QIAamp DNA mini kit (Qiagen, Hilden, Germany) according to the manufacturers' protocols. The resulting filtrate (DNA) was used as a template for PCR assay. Reference DNA from A. actinomycetemcomitans (ATCC 47318), $F$. nucleatum (ATCC 10953), P. gingivalis (ATCC 33277), $P$. intermedia (ATCC 25611) and T. denticola (B1 strain, Forsyth Dental Center) were also extracted to serve as controls. 


\section{DNA amplification}

Species-specific oligonucleotide primer pairs were used to detect the target microbial species. A pair of ubiquitous/ universal bacterial primers that matched almost all bacterial 16S rDNA genes at the same position was used as a positive control for the PCR. This served as an indicator of the presence of bacteria in the clinical samples. Table 1 contains the lists o primer pair sequences for each target bacteria species and the universal primer. Aliquots of $5 \mu \mathrm{L}$ of the supernatant from clinical samples were amplified. The PCR used to assess the occurrence of all target species was carried out using a final volume of $25 \mu \mathrm{L}$, with the reaction mix containing $11.75 \mu \mathrm{L}$ sterile water, $5 \mu \mathrm{L}$ of $10 \times$ PCR buffer (Gibco BRL, Gaithersburg, MD, USA), $2.5 \mathrm{mM} \mathrm{MgCl}_{2}, 0.4 \mu \mathrm{M}$ of each primer, 0.5 U Taq DNA polymerase (Gibco BRL) and $0.2 \mathrm{mM}$ of each deoxyribonucleoside triphosphates (dATP, dCTP, dGTP, and dTTP) (Gibco BRL).

For A. actinomycetemcomitans and P. intermedia, amplifications were programmed to run the following cycling conditions of initial denaturing at $94{ }^{\circ} \mathrm{C}$ for $0.5 \mathrm{~min} ; 36$ cycles of denaturation step at $95^{\circ} \mathrm{C}$ for $1 \mathrm{~min}$, a primer annealing step at $55^{\circ} \mathrm{C}$ for $2 \mathrm{~min}$, extension at $72{ }^{\circ} \mathrm{C}$ for $2 \mathrm{~min}$, and a final extension step of $72^{\circ} \mathrm{C}$ for $10 \mathrm{~min}$. The reference strains of A. actinomycetemcomitans (ATCC 43718) and $P$. intermedia (ATCC 25611) were used as positive controls and PCR mix without a DNA template was included as a negative control.

The PCR temperature profile for $F$. nucleatum, included 30 cycles of a denaturation step at $94{ }^{\circ} \mathrm{C}$ for $1 \mathrm{~min}$, a primer annealing step at $60^{\circ} \mathrm{C}$ for $1 \mathrm{~min}$, and an extension step at $72{ }^{\circ} \mathrm{C}$ for $2.5 \mathrm{~min}$. The reference strain (ATCC 10953) was also used as positive control and a PCR mix without a DNA template as a negative control.

The temperature profile for $P$. gingivalis is an initial denaturation step at $95{ }^{\circ} \mathrm{C}$ for $2 \mathrm{~min}$, followed by 36 cycles of a denaturation step at $94{ }^{\circ} \mathrm{C}$ for $0.5 \mathrm{~min}$, a primer annealing step at $60{ }^{\circ} \mathrm{C}$ for $1 \mathrm{~min}$, an extension step at
$72{ }^{\circ} \mathrm{C}$ for $2 \mathrm{~min}$ and a final step of $72{ }^{\circ} \mathrm{C}$ for $10 \mathrm{~min}$. The reference strain (ATCC 33277) was used as positive control and a PCR mix without a DNA template as a negative control.

Lastly, the temperature profile of $T$. denticola and the universal primer included an initial denaturation step at $95{ }^{\circ} \mathrm{C}$ for $2 \mathrm{~min}$, followed by 36 cycles of a denaturation step at $95{ }^{\circ} \mathrm{C}$ for $0.5 \mathrm{~min}$, a primer annealing step at $60{ }^{\circ} \mathrm{C}$ for $1 \mathrm{~min}$, an extension step at $72^{\circ} \mathrm{C}$ for $1 \mathrm{~min}$, and a final extension step at $72{ }^{\circ} \mathrm{C}$ for $2 \mathrm{~min}$ following the last cycle. The reference strain (B1 strain, Forsyth Dental Center) was also used as positive control and a PCR mix without a DNA template as a negative control.

All reactions were carried out in an Eppendorf Thermocycler (EPP-950000015) and amplification products (Amplicons) were finally analysed by $1 \%$ agarose gel electrophoresis in TAE buffer $[40 \mathrm{mM}$ Tris-acetate $/ 2 \mathrm{mM}$ EDTA ( $\mathrm{pH} \mathrm{8.3)]} \mathrm{performed} \mathrm{at} 70 \mathrm{~V} / \mathrm{cm}$ for $2.5 \mathrm{~h}$. Gels were stained with $0.5 \mu \mathrm{g} / \mathrm{mL}$ of ethidium bromide for 45 min, visualized under ultra-violet (UV) transilluminator and photographed using a Digital Kodak Science 120 system. A DNA ladder of $100 \mathrm{bp}$ (Promega,USA) was used as molecular weight marker.

\section{Data analysis}

The data were analysed using version 15 of the Statistical Package for Social Sciences (SPSS v15). Qualitative data were expressed as percentages and compared using Chi-square statistics. Quantitative data were summarized using mean, standard deviation and confidence interval. The data were further compared using student $t$ test and/or one-way analysis of variance (ANOVA) test as appropriate. All reported $P$ values were two-tailed; moreover, those less than 0.05 were considered statistically significant.
Table 1 PCR primer pair for detection of oral pathogens in halitosis

\begin{tabular}{ll}
\hline Bacteria & Primer pairs $\left(5^{\prime}-3^{\prime}\right)$ \\
\hline A. actinomycetemcomitans & AAA CCC ATC TCT GAG TTC TTC TTC \\
F. nucleatum & ATG CCA ACT TGA CGT TAA AT \\
& AGA GTT TGA TCC TGG CTC AG \\
P. gingivalis & GTC ATC GTG CAC ACA GAA TTG CTG \\
& AGG CAG CTT GCC ATA CTG CG \\
P. intermedia & ACT GTT AGC AAC TAC CGA TGT \\
& TTT GTT GGG GAG TAA AGC GGG \\
T. denticola & TCA ACA TCT CTG TAT CCT GCG T \\
Universal primer & TAA TAC CGA ATG TGC TCA TTT ACA T \\
& TCA AAG AAG CAT TCC CTC TTC TTC TTA \\
& GAT TAG ATA CCC TGG TAG TCC AC \\
\hline
\end{tabular}




\section{Results}

\section{Enrolled participants}

From clinical record, a total of 84 patients presented with self-complaints of halitosis at the Oral Diagnosis Clinic, University College Hospital, Ibadan between January 2008 and October 2010. Out of this number, 9 patients believed they no longer had the problem when contacted, 13 patients had relocated outside Ibadan, 17 patients could not be contacted, 2 patients were deceased, 3 patients declined to participate while 3 patients could not make the recall appointment. The remaining 37 patients who consented to participate in this study were enrolled and considered as cases while another 37 patients who came for routine Scaling and Polishing without complaint of halitosis and displayed good oral hygiene on clinical examination were enrolled as controls.

\section{Age and sex distribution of cases and controls}

The cases consisted of 24 males (64.9\%) with mean age of $37.7 \pm 10.7$ years and 13 females $(35.1 \%)$ with mean age of $40.8 \pm 14.9$ years. The male-to-female ratio was 1.9:1 and their combined mean age was $38.8 \pm 12.2$ years; while the controls consisted of 15 males (40.5\%) with mean age of $34.9 \pm 12.7$ years and 22 females $(59.5 \%)$ with mean age of $35.4 \pm 14.2$ years. Their male-to-female ratio was $1: 1.5$ and the combined mean age was $35.2 \pm 13.4$ years (Table 2). There was no significant difference between the mean ages of the cases and the controls $(t=1.2$, degrees of freedom $(d f)=72, p=0.20)$ but the sex distribution of the cases and controls showed significant statistical difference with male preponderance for cases and female preponderance for controls $\left(\chi^{2}=4.4, d f=1, p=0.04\right)$.

\section{Age group distribution of cases and controls}

The age group distributions of the cases were as follows: $2(5.4 \%)$ patients fell within the age group of $10-19$ years, $6(16.2 \%)$ were within the age group of $20-29$, while 12 (32.4\%) were within 30-39 years age group. Other age group distributions were 9 (24.3\%) patients within 40-49 years group and $8(21.6 \%)$ within the greater than 50 years group. while for the control group; $4(10.8 \%)$ patients fall within the $10-19$ years age group, $10(27.0 \%)$ within the $20-29$ years age group, $10(27.0 \%)$ within $30-39$ years age group, 7 (18.9\%) within 40-49 years group and $6(16.2 \%)$ within the greater than 50 years group (Fig. 1). There was no statistically significant difference in the age group distribution of cases and controls $\left(\chi^{2}=2.4, d f=4, p=0.67\right)$. Also, there was no significant difference in the age group distribution of cases and controls according to gender $\left(\chi^{2}=1.7, d f=4\right.$, $p=0.79$ ). However, among the cases, the age group of 30-39 years had the highest self-presentations of halitosis $12(32.4 \%)$ followed by $9(24.3 \%)$ in the $40-49$ years age group. The least self-reported complaint of halitosis 2 (5.4\%) was seen amongst the 10-19 years age group.

\section{Socioeconomic status}

Among the cases, 8 (21.6\%) were Professionals, 14 (37.8\%) were Civil Servants, 9 (24.3\%) were Students, 3 (8.1\%) fell into the Semi-skilled category and $3(8.1 \%)$ were Unskilled while among the controls, 10 (27.0\%) were Professionals, $11(29.7 \%)$ were Civil Servants, 10 (27.0\%) were Students, 4 (10.8\%) were Semi-skilled while 2 (5.4\%) were Unskilled (Fig. 2). There was no statistically significant difference

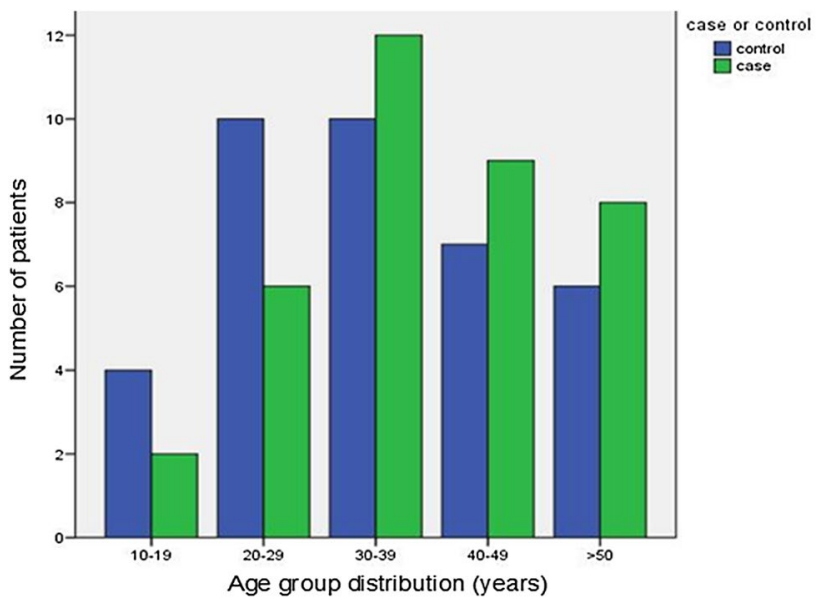

Fig. 1 Bar graph showing the age group distribution of halitosis cases and controls

Table 2 Sex distribution and mean ages of halitosis cases and controls

\begin{tabular}{|c|c|c|c|c|c|c|c|c|c|}
\hline & \multicolumn{3}{|l|}{ Males } & \multicolumn{3}{|l|}{ Females } & \multicolumn{3}{|l|}{ Total } \\
\hline & No (\%) & $\begin{array}{l}\text { Mean age } \\
\text { (years) }\end{array}$ & SD & No $(\%)$ & Mean age (yrs) & SD & No $(\%)$ & Mean age (yrs) & SD \\
\hline Control & $15(40.5 \%)$ & 34.9 & \pm 12.7 & $22(59.5 \%)$ & 35.4 & \pm 14.2 & $37(100 \%)$ & 35.2 & \pm 13.4 \\
\hline Cases & $24(64.9 \%)$ & 37.7 & \pm 10.7 & $13(35 \%)$ & 40.8 & \pm 14.9 & $37(100 \%)$ & 38.8 & \pm 12.2 \\
\hline
\end{tabular}




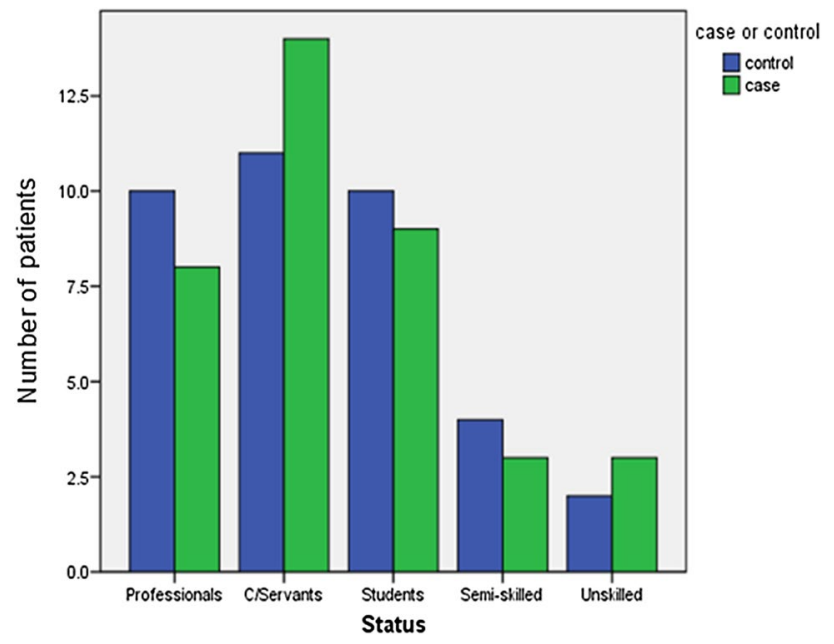

Fig. 2 Bar graph comparing the Social status of halitosis cases and controls

between the socioeconomic status of the cases and controls $\left(\chi^{2}=0.98, d f=4, p=0.91\right)$.

\section{Halimeter levels of VSC among cases and controls}

The mean of the VSC values for the cases was $107.3 \pm 58.5 \mathrm{ppb}$ while that of the controls was $98.7 \pm 34.3 \mathrm{ppb}$ (Table 3 ). There was no statistically significant difference in the mean of VSCs of cases and controls $(t=0.77, d f=72, p=0.44)$. Furthermore, the mean VSC values of males among the two groups was $102.0 \pm 49.7$ while that of the females was $104.1 \pm 46.4$ and this has no statistical significance $(t=0.18, d f=72, p=0.86)$. Also, in the case group the mean value of VSC for the males was $101.75 \pm 58.26$ and $117.46 \pm 60.03$ for the females. This difference was statistically insignificant $(t=0.78, d f=35$, $p=0.44$ ). Among the controls, the mean VSC of the males was $102.4 \pm 33.6$ and $96.1 \pm 35.4$ for the females. This was also not statistically significant $(t=0.54, d f=35, p=0.59$ ). Among the cases, the total number of patients having VSC values above the benchmark for halitosis (>160 ppb) was 8
(21.6\%) while that of the control group was 3 (8.1\%). The difference in proportion of patients was also not statistically significant $\left(\chi^{2}=1.71, d f=1, p=0.19\right.$ Yates corrected). However, the prevalence of halitosis based on VSC values above $160 \mathrm{ppb}$ was $14.9 \%$ in both groups.

\section{Socioeconomic status and VSC}

The VSC readings showed that 15 (23.8\%) Professionals, 21 (33.3\%) Civil Servants, 16 (25.4\%) Students, 7 (11.1\%) Semi-skilled and 4 (6.3\%) (Fig. 3). Unskilled patients had normal halimeter readings $(<160 \mathrm{ppb})$ while $3(27.3 \%)$ Professionals, 4 (36.4\%) Civil Servants, 3 (27.3\%) Students, none Semi-skilled and 1 (9.1\%) Unskilled patients had high values (>160 ppb) but there was no statistically significant difference between socioeconomic status of those with normal and high VSC readings $\left(\chi^{2}=1.41, d f=4, p=0.84\right)$. An interesting finding of this study is that $29(78.4 \%)$ of the cases recorded halimeter readings of less than $160 \mathrm{ppb}$ even though they believe strongly that they have oral malodor while only $8(21.6 \%)$ actually have halimeter readings

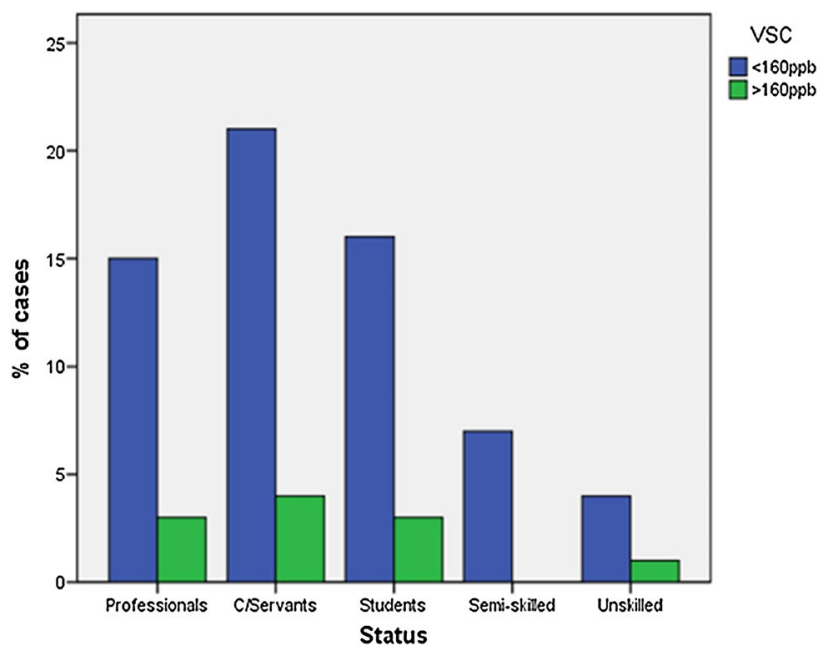

Fig. 3 Bar graph of volatile sulphur compounds (VSC) and social status of halitosis patients
Table 3 Volatile sulphur compound distribution for halitosis cases and controls

\begin{tabular}{llllllll}
\hline & $\begin{array}{l}\text { VSC levels } \\
(<160 \mathrm{ppb})\end{array}$ & $\begin{array}{l}\text { VSC levels } \\
(>160 \mathrm{ppb})\end{array}$ & Mean $(\mathrm{ppb})$ & SD & $\chi^{2}$ & $P$ value & Remark \\
\hline Controls & & & & & & & \\
Males & $14(41.2 \%)$ & $1(33.3 \%)$ & 102.4 & \pm 33.6 & 0.54 & 0.59 & Not significant \\
Females & $20(58.8 \%)$ & $2(66.7 \%)$ & 96.1 & \pm 35.4 & & & \\
Total & $34(100 \%)$ & $3(100 \%)$ & 98.7 & \pm 34.3 & & & \\
Cases & & & & & & & Not significant \\
Males & $19(65.5 \%)$ & $5(62.5 \%)$ & 101.75 & \pm 58.5 & 0.78 & 0.44 & \\
Females & $10(34.5 \%)$ & $3(37.5 \%)$ & 117.46 & \pm 60.0 & & & \\
Total & $29(100 \%)$ & $8(100 \%)$ & 107.3 & \pm 58.3 & & & \\
\hline
\end{tabular}


above the limit of social acceptance (>160 ppb). On the other hand, 34 (91.9\%) of the controls have VSC readings of less than $160 \mathrm{ppb}$ while $3(8.1 \%)$ patients have VSC values greater than the benchmark of $160 \mathrm{ppb}$ and they never complained of oral malodor. Overall, 28 (37.8\%) have halimeter readings below the normal range of $80-160 \mathrm{ppb}$ and the minimum value recorded was $33 \mathrm{ppb}$.

\section{PCR results}

\section{Non-detectable organisms}

Actinobacillus actinomycetemcomitans (Aa) and Treponema denticola (Td) Using the PCR technique for the detection of organisms, T. denticola and A. actinomycetemcomitans were not detected in the specimen samples from any of the two study groups (Fig. 4a, b).

\section{Detectable organisms}

Porphyromonas gingivalis $(\mathrm{Pg})$ Among the halitosis group, $P$. gingivalis was detected in the samples from 7 participants (18.9\%) (Fig. 5a-c), but negative in the samples from 30 participants $(81.1 \%)$ while among the control group it was only detected in 1 participant (2.7\%) but not detected in 36 participants $(97.3 \%)$. There was a statistically significant difference in the proportion of detectable Pg between the cases and controls $\left(\chi^{2}=5.05, d f=1, p=0.02\right)$.
Prevotella intermedia (Pi) Among the halitosis group, $P$. intermedia was detected in the samples from 19 participants (51.4\%) but negative in the samples from 18 participants (48.6\%) while among the control group Pi was detected in 18 participants $(48.6 \%)$ but not detected in 19 participants (51.4\%) as shown in Fig. 5d-g. There was no statistical significance in the proportion of Pi between the cases and control $\left(\chi^{2}=0.05, d f=1, p=0.82\right)$.

Fusobacterium nucleatum (Fn) Among the halitosis group, F. nucleatum was detected in the samples from 5 participants $(13.5 \%)$ but negative in the samples from 32 participants $(86.5 \%)$ as shown in Fig. 5h, while among the control group it was not detected in any of the controls. This finding was statistically significant $\left(\chi^{2}=5.36, d f=1, p=0.02\right)$.

\section{Detectable anaerobes and VSCs}

The association between the detectable anaerobes and VSC levels showed significant association between $P$. gingivalis, $P$. intermedia and $F$. nucleatum and halitosis at VSC values greater than $160 \mathrm{ppb}$ as reflected by their Odd Ratios; Pg (OR 9.9), Pi (OR 10) and Fn (OR $11.5)$ and all of these associations were statistically significant $(p<0.001, p=0.003$ and $p<0.001$, respectively) (Table 4).
Fig. 4 Polymerase chain reaction result for non-detectable organisms. Agarose gel electrophoresis shows no amplification for Actinobacillus actinomycetemcomitans (a) and Treponema denticola (b)

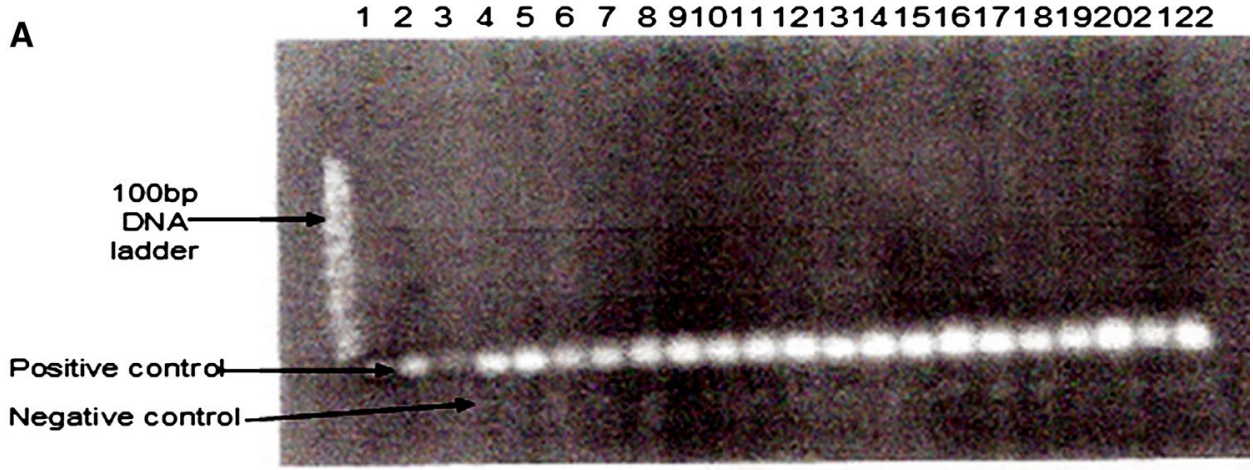

12345678910111213141516171819202122

B

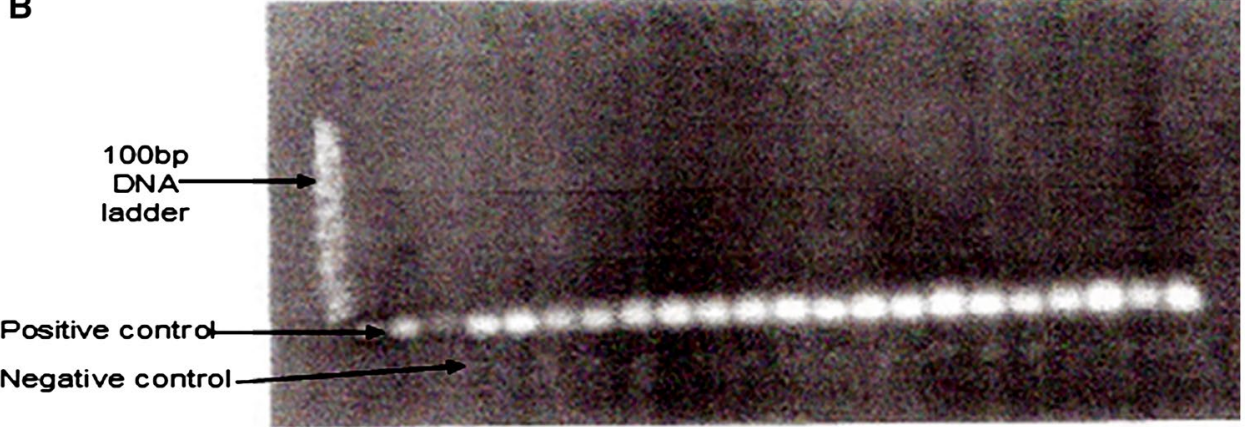



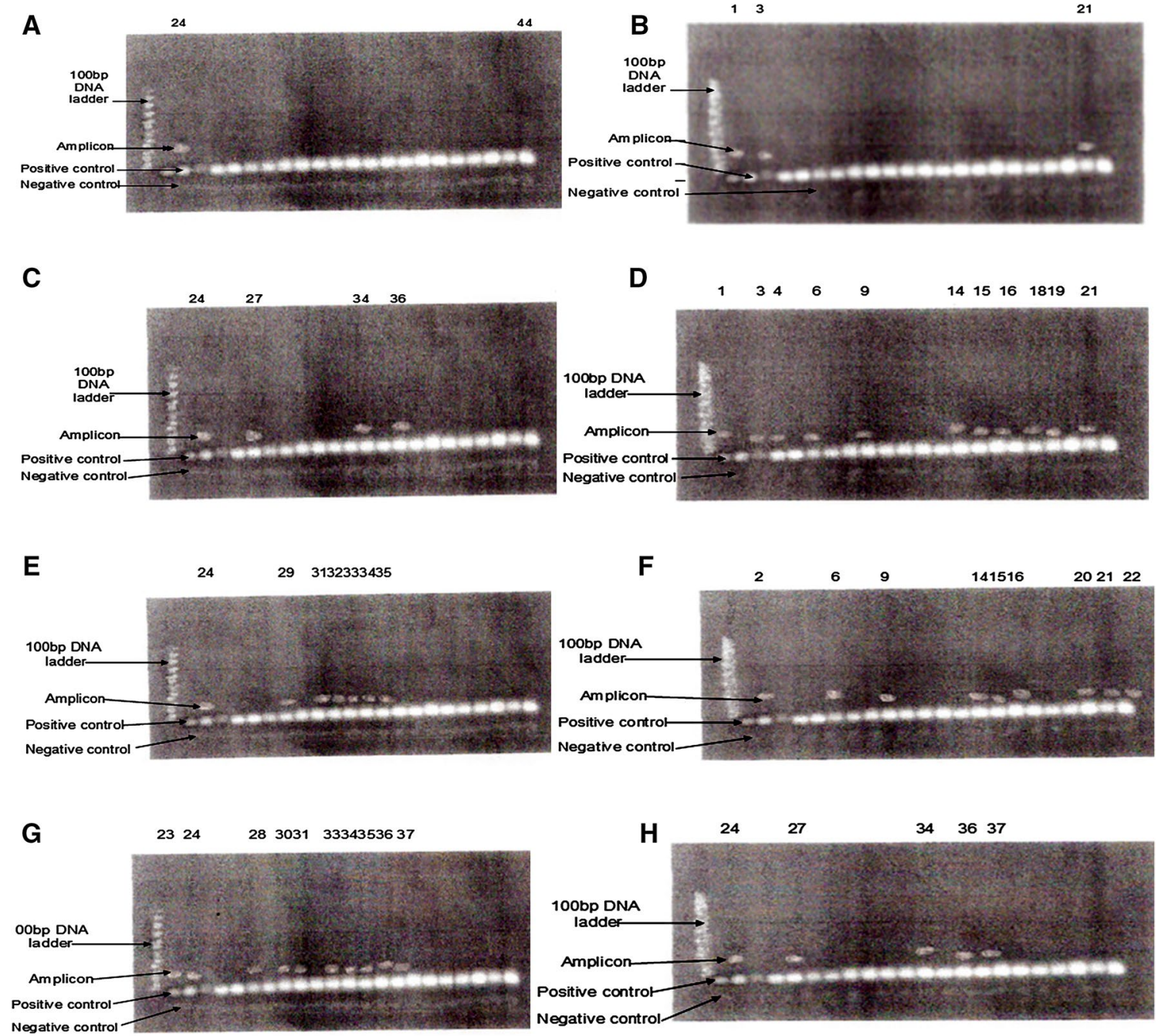

Fig. 5 Polymerase chain reaction result for detectable organisms. Agarose gel electrophoresis shows positive amplification for Porphyromonas gingivalis $($ controls $=\mathbf{a}$, cases $=\mathbf{b}, \mathbf{c})$, Prevotella intermedia $($ controls $=\mathbf{d}, \mathbf{e}$ and cases $=\mathbf{f}, \mathbf{g})$ and Fusobacterium nucleatum $(\mathbf{h})$

Table 4 Volatile sulphur compound levels in detectable anaerobic organisms

\begin{tabular}{llrr}
\hline Organisms & $\begin{array}{l}\text { Odd ratio of prevalence of organisms } \\
\text { versus VSC levels }\end{array}$ & $P$ value & Comment \\
\hline Porphyromonas gingivalis & 9.9 & $<0.001$ & Significant \\
Prevotella intermedia & 10 & 0.003 & Significant \\
Fusobacterium nucleatum & 11.5 & $<0.001$ & Significant \\
\hline
\end{tabular}

\section{Discussion}

The data presented in this study represent an insight into some bacteria on the dorsum of the tongue that may be involved in genuine physiological halitosis since a strict screening protocol [44] was employed to eliminate other factors that may be causing oral malodour.
This study revealed a statistically significant gender difference between the cases and the controls. This was also corroborated by the higher number of men presenting with self-reported cases of halitosis than the women. This is contrary to the finding from studies by Arowojolu and Dosumu [45], Bornstein et al. [1], and Iwakura et al. [46] where there was no gender difference. The disparity between the 
two results could be due to the larger samples used in these studies. However, the current finding is in tandem with the finding of Rosenberg and Leib [47] where men were found to have significantly higher levels of bad breath than the women after objective halimeter test, although the initial self-estimates of bad breath by female subjects complaining of oral malodour were significantly higher than corresponding self-scores given by male subjects. It is also in consonance with the outcome of a cross-sectional survey by Nadanovsky et al. [48] which showed that the prevalence of persistent halitosis was nearly three times higher in men than in women regardless of age. Contrary to the findings of this study, however, it has been reported that women seem to be more willing to consult healthcare professionals about their breath odour problems [1]. This could be attributable to the fact that women are usually better motivated about health concerns than men.

In another study by Iwu and Akpata [49] on cases of delusional halitosis (psychogenic), 59.4\% were single males while only $6.3 \%$ were single females. Married females constituted $31.2 \%$ of their study population. However, none of their subjects revealed any smell or any possible cause of halitosis on examination.

There was no statistically significant difference between the ages of the two groups and this result is similar to previous investigation which revealed that age does not appear to contribute to the incidence of halitosis by Miyazaki et al. [50] and Söder et al. [51]. The highest number of patients $12(32.4 \%)$ who presented with halitosis fall within the 30-39 years age group. This could be as a result of social awareness which is presumed to be highest in the third and fourth decades of life [45].

Although epidemiological data on halitosis are rare, the $14.9 \%$ prevalence of halitosis in this study compares well with the prevalence of $14.5 \%$ found both in the Arowojolu et al.'s [45] work and in a similar study carried out by Saito et al. [24]. It is however different from the prevalence of $32.5 \%$ found by Bornstein et al. [1], 43\% demonstrated by Rosenberg [52] in a similar study and $27.5 \%$ reported by Liu et al. [53].

Majority of patients 29 (78.4\%) who strongly believe they have halitosis and presented with this complaint actually have halimeter readings of less than $160 \mathrm{ppb}$. This agrees with the finding of Iwu and Akpata [45] which revealed that none of their subjects revealed any smell or any possible cause of halitosis on examination. It also corroborates the observation of both Pryse-Phillips [54] and Scully et al. [55] which stated that halitosis is a symptom related to both somatic and emotional status and that psychological disorders are strongly associated with self-reporting of the condition in some patients. Studies have shown that several potential factors can lead to exaggerated self-estimation of bad breath [47] and these include; advertisements on the subject of bad breath which may elicit unwarranted concerns in suggestible people, others may notice a bad taste in their mouth and erroneously assume that it must be related to bad breath, children of parents with bad breath may grow up inferring that they also suffer from the problem and some subjects recall having been told only once in their distant past that they had bad breath, yet continue to worry about it [56]. All the above could have been the underlying reasons that necessitated their presentation in our clinic.

Paradoxically, 3 (8.1\%) of the control group have VSC values greater than the benchmark of $160 \mathrm{ppb}$ and they never complained of oral malodour. This could be as a result of adaptation as expressed by Iwakura et al. [46] which stated that not all persons who have oral malodour are aware of halitosis whereas, majority of the patients who actually seek professional attention as a result of this condition do not have bad breath.

Twenty-eight people (37.8\%) in both groups have halimeter readings below the normal range of $80-160 \mathrm{ppb}$ and the minimum value recorded was $33 \mathrm{ppb}$. This could be ascribed to the high carbohydrate diet which is prevalent in this environment because VSCs and other malodorous compounds are mainly produced in large quantity as a result of putrefaction of proteins, mucins and peptides by microorganisms [34]. However, the other malodorous gases like indole, skatole and cadaverine which cannot be detected by the Halimeter have been reported to have low odour threshold and high odour power by Van de Velde et al. [57] and Greenmam et al. [58]. These could be more relevant to halitosis in this environment and possibly the reason why there were low VSCs values in this study. This is a very relevant finding and further studies are necessary in this environment to verify this assumption.

This study further revealed that halitosis is not affected by social status. This is not in agreement with the observation of Arowojolu and Dosumu [45] which states that people with little education and low social class tend to have mouth odour than people in the high social class and this was believed to be a reflection of the social awareness brought about by education.

Another key finding in this study was the relationship of three of the five organisms ( $P$. gingivalis, $P$. intermedia, and $F$. nucleatum) on the tongue dorsa of subjects with halitosis compared with controls at halimeter readings above $160 \mathrm{ppb}$ as reflected in their Odd Ratios. This finding shows that these three organisms produce a significantly higher amount of sulphides and it is in consonance with other findings by Nakano et al. [59], Morita and Wang [20] and De Boever and Loesche [34].

Actinobacillus actinomycetemcomitans and $T$. denticola were not detected in any of the two groups which are at variance with the observations of Yoneda et al. [23] and Persson et al. [25] which stated that these two organisms produce 
volatile sulphur compounds in large quantity. However, this does not mean that they are absolutely absent in this environment as their absence in this study could be due to the fact that the primers used may not be compatible with the strains specific to the Nigerian population due to genetic difference. There is a need to isolate these species in Nigeria and design primers specific for Nigerian strains or to attempt molecular identifications using other primers published in literatures. Furthermore, F. nucleatum is a heteregenous species with five subspecies [60]. The use of primers specific to these subspecies may likely increase the number of strains present in both patients and in controls as only one primer set was used based on the available resources. There is therefore the need for further studies in this area utilizing more primer pairs per subspecies of organisms.

One of the limitations of this study is that the PCR facility available could not quantify the number of organisms detected (which is essential for monitoring the cell number and ratio of bacteria in oral specimens like the saliva, tongue coat, and subgingival plaque). According to Awano et al. [61], most of the reported PCR-based diagnostic systems are qualitative analysis methods and are therefore unsuitable for the accurate evaluation of bacteria causing oral malodour. Quantitative analysis is essential for monitoring the cell number and ratio of bacteria in oral specimens like the saliva, tongue coat, and subgingival plaque [62-64].

A more objective result could have been obtained using a real-time PCR, Fluorescent in Situ Hybridization (FISH) and Spectrometer analysis; which future studies should consider in this environment. Also, less than half of the patients that presented with self-reported complaints of halitosis participated in this study. Finally, there is a dearth of locally published work on a similar subject resulting in limited comparison of findings with other studies in our environment.

The findings in this study indicate the potential of the application of novel molecular methods to the identification and monitoring of microbial risk factor for halitosis. The prevalence of halitosis in this study as defined by VSC level above $160 \mathrm{ppb}$ was $14.9 \%$. It was also observed that halitosis is more prevalent in males (who also tend to present with more self-reported halitosis complaints). In this study, age does not seem to contribute to the incidence of halitosis, although this needs further verification in a larger cohort. There were no differences between the VSC values between cases and controls in this study. Among halitogenic bacteria studied, F. nucleatum, $P$. gingivalis and Prevotella intermedia were found to be responsible for increased production of VSCs in halitosis patients. However, the fact that $A$. actinomycetemcomitans and $T$. denticola appear to play no part in the production of VSCs, warrants further studies. It is therefore recommended that halitosis clinics should be established in tertiary dental health institutions in Nigeria for proper information processing which is greatly needed for epidemiological characterization of this social condition and planning of oral health care. A similar study in a larger cohort, using better molecular platform is also recommended.

\section{Key points}

- We found in our study that a targeted metagenetic approach can improve the rapid diagnosis of halitosis in low- and middle-income countries.

- We also identified that this approach using the halimeter and polymerase chain reaction can provide a rapid confirmatory identification of putative halitogenic bacteria.

- Not least, based on our findings, the next step would be to develop a rapid point-of-care device for early confirmatory diagnosis of halitosis.

Acknowledgements HAA thanks the South African Medical Research Council (SAMRC) for a mid-career scientist and Self-initiated research grant; and the South African National Research Foundation (NRF) for incentive and research development grants for rated researchers.

\section{Compliance with ethical standards}

Conflict of interest The authors declare that they have no conflict of interest.

Funding No Funding.

Ethical approval All procedures performed in studies involving human participants were in accordance with the ethical standards of the institutional research committee and with the 1964 Helsinki declaration and its later amendments or comparable ethical standards.

Informed consent Informed consent was obtained from all individual participants included in the study.

\section{References}

1. Bornstein MM, Kislig K, Hoti BB, Seeman R, Lussi A. Prevalence of halitosis in the population of the city of Bern, Switzerland: a study comparing self-reported and clinical data. Eur J Oral Sci. 2009;117:261-7.

2. Van den Broek AMWT, Feenstra L, De Baat C. A review of the current literature on aetiology and measurement methods of halitosis. J Dent. 2007;35:627-35.

3. Kanehira T, Takahashi D, Honda O. Prevalence of oral malodour and the relationship with habitual mouth breathing in children. $\mathrm{J}$ Clin Paediatr Dent. 2004;28:285-8.

4. Tangerman A. Halitosis in medicine: a review. Int Dent J. 2002;52(3):201-6.

5. Tonzetich J. Direct gas Chromatographic analysis of sulphur compounds in mouth air in man. Archs Oral Biol. 1971;16:587-97.

6. Suarez F, Springfield J, Furne J, Levitt M. Differentiation of mouth versus gut as site of origin of odoriferous breath gases after garlic ingestion. Am J Physiol. 1999;276:G425-30. 
7. Stedman RL. The chemical composition of tobacco and tobacco smoke. Chem Rev. 1968;68:153-207.

8. Rosenberg M, Knaan T, Cohen D. Association among bad breath, body mass index, and alcohol intake. J Dent Res. 2007;86:997-1000.

9. Kostelc JG, Preti G, Zelson PR, Stoller NH, Tonzetich J. Salivary volatiles as indicators of periodontitis. J Periodont Res. 1980;15:185-92.

10. Goldberg S, Kozlovsky A, Gordon D, Gelernter I, Sintov A, Rosenberg M. Cadaverine as a putative component of oral malodour. J Dent Res. 1994;73:1168-72.

11. Kleinberg I, Westbay G. Oral malodour. Crit Rev Oral Biol Med. 1990;1:247-59.

12. Fukamachi H, Nakano Y, Okano S, Shibata Y, Abiko Y, Yamashita Y. High production of methyl mercaptan by methionine- $\alpha$ deamino- $\gamma$-mercaptomethane lyase from Treponema denticola. Biochem Biophys Res Commun. 2005;331:127-31.

13. Tonzetich J, McBride BC. Characterization of volatile sulphur production by pathogenic and non-pathogenic strains of oral Bacteroides. Arch Oral Biol. 1981;26:963-9.

14. Rosenberg M, Kulkarni GV, Bosy A, McCulloch CA. Reproducibility and sensitivity of oral malodour measurement with a portable sulphide monitor. J Dent Res. 1991;70:1436-40.

15. Tonzetich J. Production and origin of oral malodour; a review of mechanisms and methods of analysis. J Periodontol. 1977;48:172-81.

16. Weinberg MA, Westphal C, Froum SJ. Comprehensive periodontics for the dental hygienist. 2nd ed. New Jersey: Prentice Hall; 2006. p. 337-46.

17. Morita M, Wang HL. Relationship of sulcular sulphide level to severity of periodontal disease and BANA test. J Periodontol. 2001;72:74-8.

18. Shimura M, Yasuno Y, Iwakura M, Sakai S, Suzuki K, Sakamoto $\mathrm{S}$. A new monitor with a zinc-oxide thin film semiconductor sensor for the measurement of volatile sulphur compounds in mouth air. J Periodontol. 1996;67:396-402.

19. Replogle WH, Beebe DK. Halitosis. Am Fam Physician. 1996;53(1215-1218):1223.

20. Morita M, Wang HL. Association between oral malodour and adult periodontitis: a review. J Clin Periodontol. 2001;28:813.

21. Aas JA, Paster BJ, Stokes LN, Olsen I, Dewhirst F. Defining the normal bacterial flora of the oral cavity. J Clin Microbiol. 2005;43:5721-32.

22. Sharma NC, Galustians HJ, Qaqish J. The clinical effectiveness of a dentifrice containing triclosan and a copolymer for controlling breath odour measured organoleptically twelve hours after toothbrushing. J Clin Dent. 1999;10(4):131-4.

23. Yoneda M, Naito T, Suzuki N. Oral malodour associated with internal resorption. J Oral Sci. 2006;48:89-92.

24. Saito H, Kawaguchi Y. Halitosis prevention campaign. A report of oral health promotion activities in Japan. Int Dent J. 2002;52:197-200.

25. Persson S, Claesson R, Carlsson J. The capacity of subgingival microbiotas to produce volatile sulphur compounds in human serum. Oral Microbiol Immunol. 1989;4:169-72.

26. Rosenberg M. Bad breath: research perspectives. Tel Aviv: Ramot; 1977.

27. Haraszthy VI, Zambon JJ, Sreenivasan PK, Zambon MM, Gerber D, Rego R. Identification of oral bacterial species associated with halitosis. J Am Dent Assoc. 2007;138(8):1113-20.

28. Kazor CE, Mitchell PM, Lee AM, Stokes LN, Loesche WJ, Dewhirst FE. Diversity of bacterial populations on the tongue dorsa of patients with halitosis and healthy patients. J Clin Microbiol. 2003;41:558-63.
29. Yaegaki K, Coil JM, Kamemizu T, Miyazaki H. Tongue brushing and mouth rinsing as basic treatment measures for halitosis. Int Dent J. 2002;52:192-6.

30. Cicek Y, Orbak R, Tezel A, Orbak Z, Erciyas K. Effect of tongue brushing on oral malodour in adolescents. Pediatr Int. 2003;45:719-23.

31. Yaegaki K. Composition of malodourous gases and periodontitis. J Dent Res. 1990;69:382.

32. Almas K, Al-Sanawi E, Al-Shahrani B. The effect of tongue scraper on mutans streptococci and lactobacilli in patients with caries and periodontal disease. Odonto-stomatol Trop. 2005;28(109):5-10.

33. Kostelc JG, Zelson PR, Preti G, Tonzetich J. Quantitative differences in volatiles from healthy mouths and mouths with periodontitis. Clin Chem. 1981;27:842-5.

34. De Boever EH, Loesche WJ. Assessing the contribution of anaerobic microflora of the tongue to oral malodour. J Am Dent Assoc. 1995;126:1384-93.

35. Hartley MG, El-Maaytah MA, McKenzie C, Greenman J. The tongue microbiota of low odour and malodourous individuals. Microb Ecol Health Dis. 1996;9:215-23.

36. McNamara TF, Alexander JF, Lee M, Plains M. The role of microorganisms in the production of oral malodour. Oral Surg. 1972;34:41-8.

37. Quirynen M, van Eldere J, Pauwels M, Bollen CML, van Steenberghe D. In vitro volatile sulphur compound production of oral bacteria in different culture media. Quintessence Int. 1999;30:351-6.

38. Bernardi S, Continenza MA, Al-Ahmad A, Karygianni L, Follo M, Filippi A, Macchiarelli G. Streptococcus spp. and Fusobacterium nucleatum in tongue dorsum biofilm from halitosis patients: a fluorescence in situ hybridization (FISH) and confocal laser scanning microscopy (CLSM) study. New Microbiol. 2019;42(2):108-13.

39. Hess J, Greenman J, Duffield J. Modelling oral malodour from a tongue biofilm. J Breath Res. 2008;2(1):017003.

40. Migliario M, Rimondini L. Oral and non oral diseases and conditions associated with bad breath. Minerva Stomatol. 2011;60(3):105-15.

41. Waler SM. The effect of zinc-containing chewing gum on volatile sulphur-containing compounds in the oral cavity. Acta Odontol Scand. 1997;55:198-200.

42. Hartley G, McKenzie C, Greenman J, El-Maaytah MA, Scully C, Porter S. Tongue microbiota and malodour. Microb Ecol Health Dis. 1999;11:226-33.

43. Relman DA. New technologies, human microbe interactions, and the search for previously unrecognized pathogens. J Infect Dis. 2002;186(2):S254-8.

44. Donaldson AC, Riggio MP, Rolph HJ, Bagg J, Hodge PJ. Clinical examination of subjects with halitosis. Oral Dis. 2006;13:63-70.

45. Arowojolu MO, Dosumu EB. Halitosis (Fetor oris) in Patients seen at the Periodontology clinic of the University College Hospital, Ibadan. The Niger Postgrad Med J. 2004;11(3):221-4.

46. Iwakura M, Yasuno Y, Shimura M, Sakamoto S. Clinical characteristics of halitosis: differences in two patient groups with primary and secondary complaints of halitosis. J Dent Res. 1994;73:1568-74.

47. Rosenberg M, Leib E. Experiences of an Israeli malodour clinic. In: Rosenberg M, editor. Bad breath: research perspectives. Tel Aviv: Ramot Publishing-Tel Aviv University; 1995. p. 137-48.

48. Nadanovsky P, Carvalho LBM, de Leon AP. Oral malodour and its association with age and sex in a general population in Brazil. Oral Dis. 2007;13:105-7.

49. Iwu CO, Akpata O. Delusional halitosis. Review of literature and analysis of 32 cases. Br Dent J. 1989;167:294-6. 
50. Miyazaki H, Sakao S, Katoh Y, Takehara T. Correlation between volatile sulphur compounds and certain oral health measurements in the general population. J Periodontol. 1995;66:679-84.

51. Söder B, Johansson B, Söder PO. The relation between fetor ex ore, oral hygiene and periodontal disease. Swed Dent J. 2000;24:73-82.

52. Rosenberg M. Bad breath and periodontal disease, how related are they? J Clin Periodontol. 2006;33:29-30.

53. Liu XN, Shinada K, Chen XC, Zhang BX, Yaegaki K, Kawaguchi Y. Oral malodour related parameters in the Chinese general population. J Clin Periodontol. 2006;33:31-6.

54. Pryse-Phillips W. An olfactory reference syndrome. Aeta Psychiat Seand. 1971;47:484-510.

55. Scully C, El-Maaytah M, Porter SR, Greenman J. Breath odor: etiopathogenesis, assessment and management. Eur J Oral Sci. 1997;105:287-93.

56. Rosenberg M, Kozlovsky A, Gelernter I, Cherniak O, Cgabby J, Baht R, et al. Self estimation of oral malodour. J Dent Res. 1995;74(9):1577-82.

57. Van den Velde S, van Steenberghe D, Van hee P, Quirynen M. Detection of odourous compounds in breath. J Dent Res. 2009;88:285-9.

58. Greenman J, El Maaytah M, Duffield J, Spencer P, Rosenberg L, Corry D. Assessing the relationship between concentrations of malodor compounds and odour scores from judges. J Am Dent Assoc. 2005;136:749-57.
59. Nakano Y, Yoshimura M, Koga T. Correlation between oral malodour and periodontal bacteria. Microbes Infect. 2002;4:679-83.

60. Bolstad AI, Jensen HB, Bakken V. Taxonomy, biology, and periodontal aspects of Fusobacterium nucleatum. Clin Microbiol Rev. 1996;9(1):55-71.

61. Awano S, Gohara K, Kurihara E. The relationship between the presence of periodontopathogenic bacteria in saliva and halitosis. Int Dent J. 2002;52:212-6.

62. Yoshida A, Suzuki N, Nakano Y. Development of a 5' fluorogenic nuclease- based real-time PCR assay for quantitative detection of Actinobacillus actinomycetemcomitans and Porphyromonas gingivalis. J Clin Microbiol. 2003;41:863-6.

63. Kuboniwa M, Amano A, Kimura RK. Quantitative detection of periodontal pathogens using real-time polymerase chain reaction with TaqMan probes. Oral Microbiol Immunol. 2004;19:196-200.

64. Suzuki N, Yoshida A, Saito T. Quantitative microbiological study of subgingival plaque by real-time PCR shows correlation between levels of Tannerella forsythensis and Fusobacterium spp. J Clin Microbiol. 2004;42:2255-7.

Publisher's Note Springer Nature remains neutral with regard to jurisdictional claims in published maps and institutional affiliations. 